\section{Clinical implications}

- Young adults and children now commonly survive treatment for cancer and subsequently want to have a family

- Many fear that the toxic treatment they received for cancer will affect their children

- This study shows that the risk of having a child with congenital anomalies was not increased among parents who had been treated for cancer

- For live births there was no relation between increasing toxicity of treatment and congenital anomalies

- Cancer patients can be reassured that any liveborn offspring are unlikely to be affected by cancer treatment
3 Balis FM, Holcenberg JS, Poplack DG. General principals of chemotherapy. In: Pizzo AA, Poplack DG, eds. Principals and practice of pediatric oncology. Philadelphia: J B Lippincott, 1989:165-205.

4 Kirk KM, Lyon MF. Induction of congenital anomalies in offspring of female mice exposed to varying doses of X-rays. Mutat Res 1982;106:73-83.

5 Nomura T. X-ray and chemically induced germ-line mutation causing phenotypical anomalies in mice. Mutat Res 1988;198:309-20.

6 Trasler JM, Hales BF, Rabaire B. Paternal cyclophosphamide treatment of rats causes fetal loss and malformations without affecting male fertility. Nature 1985;316:144-6.

7 Hawkins MM. Is there evidence of a therapy-related increase in germ cell mutation among childhood cancer survivors? I Natl Cancer Inst 1991;83 $1643-50$

8 Li FP, Gimbrere K, Gelber RD, Sallan SE, Flamant F, Green DM, et al. Outcome of pregnancy in survivors of Wilm's tumor. JAMA $1987 ; 257^{2}$ 216-9.

9 Hawkins MM, Smith RA. Pregnancy outcomes in childhood cancer survivors: probable effects of abdominal irradiation. Int $\mathcal{f}$ Cancer 1989;43:399-402.

10 Mulvihill JJ, McKeen EA, Rosner F, Zarrabi MH. Pregnancy outcomes in cancer patients. Experience in a large cooperative group. Cancer 1987;60 cancer patien $1143-50$.

11 Mulvihill JJ. Sentinel and other mutational effects in offspring of cancer survivors. Prog Clin Bio Res 1990;340:179-86.

born offspring, the probability of having a child with a congenital anomaly is not appreciably different for those who have had cancer or been treated for cancer from that for the general population.

We acknowledge the help from the staff who worked on this study. We also thank the Office of the Registrar General, Statistics Canada, the Canadian congenital anomalies surveillance system, and the hospitals, regional cancer centres, and the Princess Margaret Hospital for data used in this study. The cooperation of the staff at the Ontario cancer registry and in the information systems division of the Ontario Cancer Treatment and Research Foundation is also appreciated. We thank Dr David Carr for his help in assigning aetiologoical diagnoses to the congenital anomalies. Drs A B Miller and John Frank provided helpful suggestions throughout the study. This study was funded by the Ontario Ministry of Health. LD was supported by a PhD fellowship and DJT by a national health research scholar award from the National Health Research and Development Program of Health and Welfare Canada.

1 Young JL, Ries LG, Silverberg E, Horm JW, Miller RW. Cancer incidence, survival and mortality for children younger than age 15 years. Cancer 1986;58:598-602

2 Hawkins MM. Long term survival and cure after childhood cancer. Arch Dis Child 1989;64:798-807.
12 World Health Organisation. International Classification of Diseases. Geneva: WHO, 1977 .

13 Howe GR, Lindsay J. A generalized iterative record linkage system for use in medical follow-up studies. Comput Biomed Res 1981;14:327-40. et al. Effects of treatment on fertility in long term survivors of childhood or adolescent cancer. $N$ Engl f Med 1987;317:1315-21.

15 Chabner BA, Myers CE. Clinical pharmacology of cancer chemotherapy. In: DeVita VT Jr, Hellman S, Rosenberg SA, eds. Cancer: principals and practice of oncology. Philadelphia: J B Lippincott, 1982:156-97.

16 Baird PA, Anderson TW, Newcombe HB, Lowry RB. Genetic disorders in children and young adults: a population study. Am F Hum Genet 1988;42 children

17 SAS Institute, SAS version 5. Cary, NC: SAS, 1985

18 EGRET Seattle, Washington: Statistics and Epidemiology Research Corporation, 1988.

19 Breslow NE, Day NE. Statistical methods in cancer research. Vol 1. The analysis of case-control studies. Lyon: International Agency for Research on Cancer, 1980. (IARC scientific publication No 32.)

20 Rothman KJ. Modern epidemiology. Toronto: Little, Brown, 1986.

21 Czeizel A. Population surveillance of sentinel anomalies. Mutat Res 1989;212:3-9.

22 Green DM, Zevon MA, Lowrie G, Seigelstein N, Hall B. Congenital anomalies in children of patients who received chemotherapy for cancer in childhood and adolescence. $N$ Engl F Med 1991;325:141-6.

23 Gardner MJ, Snee MP, Hall AJ, Powell CA, Downes S, Terrell JD. Results of case-control study of leukaemia and lymphoma among young people near Sellafield nuclear plant in West Cumbria. BMJ 1990;300:423-9.

24 Blatt J, Bleyer WA. Late effects of childhood cancer and its treatment. In: Pizzo AA, Poplack DG, eds. Principals and practice of pediatric oncology. Philadelphia: J B Lippincott, 1989:1003-25.

(Accepted 11 May 1993)
14 Byrne J, Mulvihill JJ, Myers MH, Connelly RR, Naughton MD, Krauss MR,

\title{
Factors affecting uptake of measles, mumps, and rubella immunisation
}

\author{
Jun Li, Brent Taylor
}

Abstract

Objective-To study factors affecting uptake of measles, mumps, and rubella immunisation.

Design-Cohort study using data from computerised child health systems.

Setting-10 health districts in North East Thames and North West Thames regions.

Subjects - 7841 children born in January to March 1990 and resident in the districts up till the end of October 1991.

Main outcome measures-Overall uptake of measles, mumps, and rubella immunisation, varia-

Department of Community Child Health, Royal Free Hospital School of Medicine, London NW3 2QG

Jun $\mathrm{Li}$, research fellow Brent Taylor, professor of community child health

Correspondence to: Dr Li.

BMf 1993;307:168-71 registered for immunisation (general practitioner or clinic), and one parent family status.

Conclusions-Many districts have difficulties in meeting the $90 \%$ target for measles, mumps, and rubella immunisation, mainly because of the characteristics of their local population. To increase overall coverage, the health service should target families with adverse factors, especially those whose children have missed previous immunisations.

\section{Introduction}

In October 1988 the combined measles, mumps, and rubella vaccine replaced monocomponent measles vaccine in the routine childhood immunisation programme for the United Kingdom.' This change was partly to improve rubella coverage as well as to introduce protection against mumps into the schedule. The change was also hoped to improve uptake of measles immunisation, about which there had been widespread concern in Britain..$^{2-5}$ Coverage with measles, mumps, and rubella vaccine has dramatically increased protection against measles in the country as a whole. ${ }^{6}$ The improved uptake of measles, mumps, and 
rubella vaccine compared with monovalent measles vaccine is believed to relate to various strategies including specific campaigns. ${ }^{89}$ Despite an overall national and local increase in coverage of measles, mumps, and rubella vaccine there is still a wide variation between localities, and the $90 \%$ target $^{110}$ has not been met in many local district health authorities."

Reasons for disappointingly low uptake relate both to deficits in the services provided and to the characteristics of the client populations. ${ }^{7}$ There seem to have been few studies, however, especially studies on a large scale, evaluating the performance of the measles, mumps, and rubella immunisation programme, exploring possible reasons for variations in uptake. This paper presents the results of an epidemiological assessment of uptake of measles, mumps, and rubella vaccine, including factors influencing uptake for a three month birth cohort in 10 districts from North East Thames and North West Thames regions.

\section{Methods}

Data source and study population-This study was a part of a project evaluating child health computing systems that was conducted in 10 districts (five each) from North East Thames and North West Thames regions. The selection of study districts was not completely random; five districts were selected in North East Thames taking into account geographic area (including rural, suburban, and inner city districts), Jarman score (covering a wide range of the score), duration of using the new child health system ("old" as well as "new" users were included), and geographic accessibility of the district (the project included on site interviewing of health professionals). Each of these five North East Thames districts was matched with one from North West Thames region on sociodemographic determinants and geographic similarities. Data were collected from the child health computing systems after permission had been obtained from the health authority managers and the responsible staff of the child health departments. The study subjects were the whole resident child population born between January and March 1990 and aged 19 to 21 months at the time the data were collected.

Outcome variable-According to the national schedule for measles, mumps, and rubella immunisation, all children should receive the vaccine between the ages of $12-18$ months, usually before 15 months. ${ }^{112}$ Therefore all study children in this three month birth cohort should have received the vaccine by the time of data collection. The outcome of this study was whether or not a child had been vaccinated against measles, mumps, and rubella. The uptake rate of the vaccine was calculated from the number of resident children recorded as having been immunised, expressed as a percentage of the total number of resident children.

Predictor variables-All factors suspected to be potentially associated with uptake and available in the systems were investigated. These factors included: (i) type of district - categorised on geographic criteria and Jarman score ${ }^{13}$ into low deprived rural and suburban districts (Jarman score < $<$; four districts) and high deprived inner city districts (Jarman score $\geqslant 0$; six districts); (ii) birth order-grouped into five

TABLE I-Uptake rates of measles, mumps, and rubella vaccine in 10 study districts in North East Thames and North West Thames regions among resident children aged 19-21 months (born between fanuary and March 1990)

\begin{tabular}{|c|c|c|c|c|c|c|c|c|c|c|c|}
\hline & \multicolumn{6}{|c|}{ Inner city districts } & \multicolumn{4}{|c|}{ Rural or suburban districts } & \multirow[b]{2}{*}{ Overall } \\
\hline & 1 & 2 & 3 & 4 & 5 & 6 & 7 & 8 & 9 & 10 & \\
\hline $\begin{array}{l}\text { No vaccinated } \\
\text { Uptake rate }(\%)\end{array}$ & $\begin{array}{l}785 \\
81 \cdot 3\end{array}$ & $\begin{array}{l}287 \\
68 \cdot 7\end{array}$ & $\begin{array}{l}616 \\
81 \cdot 2\end{array}$ & $\begin{array}{c}204 \\
76 \cdot 4\end{array}$ & $\begin{array}{l}729 \\
74 \cdot 2\end{array}$ & $\begin{array}{l}571 \\
72 \cdot 0\end{array}$ & $\begin{array}{c}574 \\
87.5\end{array}$ & $\begin{array}{l}752 \\
91 \cdot 4\end{array}$ & $\begin{array}{r}1217 \\
87 \cdot 6\end{array}$ & $\begin{array}{l}680 \\
86 \cdot 4\end{array}$ & $\begin{array}{r}6415 \\
81 \cdot 8\end{array}$ \\
\hline
\end{tabular}

$\chi^{2}=250 \cdot 2, \mathrm{p}<0 \cdot 001$ categories, from only child to fifth plus; (iii) immunisation location-defined according to where the child was registered for immunisation: at a general practitioner's surgery or at a community child health clinic; (iv) maternal age-age of the mother when she gave birth to the study child: it was initially divided into four age groups, $<20$ years, $20-29$ years, 30-39 years, and $\geqslant 40$ years, but preliminary analyses showed no significant difference between the first and fourth groups and between the second and third groups in terms of the uptake rates so maternal age was regrouped for the multivariate analyses into two: teenaged or older mothers $(<20$ or $\geqslant 40$ years) and mothers aged 20-39 years; (v) birth weight-grouped into $<2500 \mathrm{~g}$ (low birth weight) and $\geqslant 2500 \mathrm{~g}$ (normal birth weight); (vi) type of resident-whether a child was a continuous resident (living in the current resident district since birth) or a moved in resident (moved into the current resident district since birth); (vii) primary immunisation status-defined as "completed" if a child had received his or her complete (three doses) primary course of immunisations (diphtheria, pertussis, and tetanus or diphtheria and tetanus and polio vaccines), and "not completed" if the primary course of immunisations had not been completed; (viii) type of family - one parent or two parent; (ix) child sex-male or female; and ( $x$ ) type of child health computer systems-the national child health computer system or the North East Thames regional interactive child health system (RICHS).

Data analysis - The analysis proceeded in two steps. Firstly, a univariate analysis was performed to investigate the association between uptake of measles, mumps, and rubella vaccine and the individual variables. Unadjusted odds ratio and the $95 \%$ confidence interval for the odds ratio were calculated. The $\chi^{2}$ test was used to assess the association between vaccine uptake and each of the predictor variables. Secondly, immunisation status was modelled with logistic regression, using for predictors those variables that were significantly associated with immunisation status at the $p \leqslant 0.05$ level by $\chi^{2}$ testing. New variables were included in the model if they significantly improved the predictive power of the logistic regression equation at the set $\mathrm{p}$ level. Children with missing data on a predictor variable were excluded from the analysis of that variable but as large a data set as possible was used for each analysis. The SAS package ${ }^{14}$ was used for the analyses.

\section{Results}

Table I lists the uptake rates of measles, mumps, and rubella immunisation in the 10 districts; the rates ranged from $68 \cdot 7 \%$ to $91.4 \%$, giving an overall uptake of $81.8 \%$ in these 10 districts. The uptake rates were $83 \cdot 2 \%, 81 \cdot 2 \%$, and $81 \cdot 1 \%$, respectively, for children aged 19, 20, and 21 months, showing little evidence $(p=0.09)$ that there was late uptake of immunisation for this three month birth cohort.

Table II shows the associations between the uptake of measles, mumps, and rubella vaccine and 10 factors. Birth weight and sex of children did not influence uptake. The eight other variables were significantly associated with uptake and were included as regression terms in the multivariate logistic regression analysis.

Maternal age, type of resident, and type of child health computer system were not included in the final logistic regression model at the 5\% level, suggesting that they lost their significance when other variables were adjusted for. Table III lists the odds ratios of being vaccinated for categories of each variable. The odds ratios of less than 1.0 for the two-categorical variables means that a child in a group was less likely to be vaccinated than a child in the reference group (odds 
ratio $=1 \cdot 0$ ). For instance, the odds of having received measles, mumps, and rubella vaccine for a child who had not completed the primary immunisations was $4 \%$ the odds for a child who had; the odds for a child who was registered at a child health clinic was about $80 \%$ the odds for one attending a general practice. The model suggested that each "unit" of increase in birth order would be responsible for a decrease in the odds by about $20 \%$.

To investigate the association between pertussis and measles, mumps, and rubella immunisations we examined only those study subjects who had completed their primary immunisations. It was found that of these children, $308(4 \cdot 4 \%)$ had not had pertussis vaccine, and the uptake of measles, mumps, and rubella immunisation for these 308 children was $77.9 \%$ compared with $90 \cdot 1 \%$ for children who received diphtheria, pertussis, and tetanus vaccine. The logistic regression model indicated that the odds of being vaccinated agaisnt measles, mumps, and rubella for children who had not had pertussis vaccine was $43 \%$ the odds for children receiving the vaccine, allowing for other factors (table IV).

\section{Discussion}

This study identified five factors associated with uptake of measles, mumps, and rubella immunisation;

TABLE II-Proportion of population by each variable with unadjusted odds ratios for the association between children's and mothers' characteristics and uptake of measles, mumps, and rubella vaccine among children aged 19-21 months (born between fanuary and March 1990) resident in 10 study districts

\begin{tabular}{|c|c|c|c|}
\hline Variable & $\%(\mathrm{No})$ & $\begin{array}{c}\text { Odds ratio } \\
(95 \% \text { confidence interval })\end{array}$ & $\mathrm{p}$ Value \\
\hline \multicolumn{4}{|l|}{ Birth weight (grams): } \\
\hline$<2500$ & $92 \cdot 7(6613)$ & 1.00 & \\
\hline$\geqslant 2500$ & $7 \cdot 3(521)$ & $0.96(0.75$ to 1.22$)$ & 0.77 \\
\hline \multicolumn{4}{|l|}{ Immunisation location: } \\
\hline General practices & $62 \cdot 8(4531)$ & 1.00 & \\
\hline Health clinics & $37 \cdot 2(2683)$ & $0.43(0.38$ to 0.50$)$ & $<0.001$ \\
\hline \multicolumn{4}{|l|}{ Maternal age (years): } \\
\hline$<20$ & $5 \cdot 2(362)$ & 1.00 & \\
\hline $20-29$ & $54 \cdot 8(3849)$ & $1.30(1.01$ to 1.67$)$ & $<0.05$ \\
\hline $30-39$ & $37 \cdot 6(2638)$ & $1.38(1.05$ to 1.83$)$ & $<0.05$ \\
\hline$\geqslant 40$ & $2.5(177)$ & $1.18(0.75$ to 1.88$)$ & 0.47 \\
\hline \multicolumn{4}{|l|}{ Birth order: $†$} \\
\hline First & $43 \cdot 2(3012)$ & $1 \cdot 00$ & \\
\hline Second & $32 \cdot 3(2253)$ & $0.97(0.83$ to 1.14$)$ & 0.70 \\
\hline Third & $14 \cdot 9(1037)$ & $0.58(0.48$ to 0.69$)$ & $<0.001$ \\
\hline Fourth & $5 \cdot 6(394)$ & $0.50(0.39$ to 0.64$)$ & $<0.001$ \\
\hline Fifth or more & $4 \cdot 1(284)$ & $0.30(0.23$ to 0.40$)$ & $<0.001$ \\
\hline \multicolumn{4}{|l|}{ One parent family: } \\
\hline No & $85 \cdot 7(5771)$ & $1 \cdot 00$ & \\
\hline Yes & $14 \cdot 3(964)$ & $0.75(0.63$ to 0.89$)$ & $<0.01$ \\
\hline \multicolumn{4}{|l|}{ Primary immunisations completed: } \\
\hline Yes & $88 \cdot 5(6935)$ & 1.00 & \\
\hline No & $11 \cdot 6(906)$ & $0.03(0.02$ to 0.04$)$ & $<0.001$ \\
\hline \multicolumn{4}{|l|}{ Type of resident: } \\
\hline Continuous & $85 \cdot 8(6728)$ & 1.00 & \\
\hline Moved in & $14 \cdot 2(1113)$ & $0.40(0.34$ to 0.46$)$ & $<0.001$ \\
\hline \multicolumn{4}{|l|}{ Type of resident district: } \\
\hline Low deprived rural or suburban & $46 \cdot 6(3656)$ & 1.00 & \\
\hline High deprived inner city & $53 \cdot 4(4185)$ & $0.43(0.38$ to 0.49$)$ & $<0.001$ \\
\hline \multicolumn{4}{|l|}{ Sex: } \\
\hline Male & $50 \cdot 8(3982)$ & 1.00 & \\
\hline Female & $49 \cdot 2(3858)$ & $1.05(0.94$ to 1.18$)$ & 0.39 \\
\hline \multicolumn{4}{|l|}{ Serviced by: } \\
\hline National system & $46 \cdot 2(3622)$ & 1.00 & \\
\hline Regional system & $53.8(4219)$ & $0.84(0.74$ to 0.94$)$ & $<0.01$ \\
\hline
\end{tabular}

tp Value for $\chi^{2}$ test for trend also $<0.01$
TABLE IV-Estimated odds ratios for uptake of measles, mumps, and rubella immunisation by each factor after controlling for others in resident children who completed three doses of their primary immunisation course

\begin{tabular}{ll}
\hline Factor & Odds ratio $(95 \%$ confidence interval) \\
\hline Primary immunisations received: & \\
$\quad$ Diphtheria, pertussis, tetanus & 1.00 \\
$\quad$ Diphtheria and tetanus & $0.43(0.31$ to 0.62$)$ \\
Type of resident district: & 1.00 \\
$\quad$ Low deprived rural or suburban & $0.59(0.48$ to 0.72$)$ \\
$\quad$ High deprived inner city & $0.80(0.74$ to 0.87$)$ \\
Birth order & 1.00 \\
Immunisation location: & $0.80(0.65$ to 0.98$)$ \\
$\quad$ General practices & 1.00 \\
$\quad$ Child health clinics & $0.66(0.53$ to 0.84$)$ \\
One parent family: & \\
No &
\end{tabular}

the most important predictor for uptake was found to be the primary immunisation status. Children who did not receive their primary immunisations at all were also less likely to have received measles, mumps, and rubella immunisation. This strong association between uptake of primary and measles, mumps, and rubella immunisation suggests the existence of a group of children with extreme problems in being vaccinated. Some families, especially in inner city districts with high deprivation, are highly mobile, living in temporary accommodation, and these families are extremely difficult to trace, so that immunisation appointments are less likely to reach them. ${ }^{15}$ Some children may have been vaccinated by a private doctor, few of whom contribute to a computerised immunisation system. The first factor is more likely in inner city districts while the second may be appreciable in rural and suburban areas. The group may include certain families who refuse all immunisation procedures or who prefer an alternative method, ${ }^{1516}$ and others who are advised not to be immunised due to "contraindications" (many of which might be false) to both primary and measles, mumps, and rubella immunisations. ${ }^{12}$ The association between uptake of pertussis and measles, mumps, and rubella immunisation suggests that uncertainties about these two vaccines were more likely than those about other vaccines.

We have previously reported that general practices do better than community child health clinics in terms of providing primary immunisations. ${ }^{17}$ This finding was confirmed in the present study for uptake of measles, mumps, and rubella vaccine. General practitioners may do better than health clinics for immunisations because general practitioners are encouraged to meet the target for immunisation payments in the new practitioner $\operatorname{contract}^{18}$; communication between general practitioners and families is more efficient with more effective consultation with regard to immunisations ${ }^{15}$; and immunisation session times in general practice may be more flexible and convenient for clients, especially for working parents or parents with other childern (most surgeries run evening or weekend sessions). ${ }^{15}$

Birth order was associated with uptake of measles, mumps, and rubella immunisation. Children from larger families have been found to have lower immunisation uptake. ${ }^{15} 19-21$ Children living with one parent were also less likely to receive measles, mumps, and rubella vaccine, a finding consistent with earlier results. ${ }^{19}$ Parents with other children to take care of or single parents with little support may find it difficult to get around to having their children immunised..$^{1519}$ These families may need additional support from community health staff such as health visitors or practice nurses and should be particularly targeted. Making immunisation sessions more accessible, at times when parents find it easier to attend; extending crèche facilities in health clinics for siblings; providing opportunistic immunisations when children appear at
Low deprived rural or su
High deprived inner city High depr
Birth order

Immunisation location

General practices

Child health clinic

No

Yes
1.00

$0.67(0.56$ to 0.80$)$

1.00

1.00

0.75 ( 0.60 to 0.93$)$ 
general practices, health clinics, or hospitals for other reasons; and providing a domestic immunisation service by health visitors or other community staff for families with particular difficulties should improve immunisation uptake..$^{22} 23$

"Inner city" status has been identified in almost all studies to be an important risk factor associated with childhood immunisation uptake. Although there may be differences in immunisation practice between inner cities and rural or suburban areas, we believe that the major contribution to lower uptake of immunisations in inner cities is due to the make up of the population in such disadvantaged areas. For instance, inner city districts tend to have higher proportions of families from minority ethnic groups; in lower social classes; with more children, only one parent, or very young or old mothers; and with more likelihood of being unstable. Such adverse factors seem more likely to directly affect poor immunisation uptake than does inner city status. We believe that to improve uptake of measles, mumps, and rubella immunisation it would be more productive to target specific groups rather than to broadly target inner city populations.

From the routinely collected child health data we found that the overall coverage rate of measles, mumps, and rubella vaccine for the three month birth cohort aged 19 to 21 months in the 10 districts was about $82 \%$, which is disappointing compared with the $90 \%$ target and the $92 \%$ national average coverage rate for children born in the same period. "The lower rate from our study in comparison with "COVER" data" relates to three factors. Firstly, our evaluation was carried out when the study children were aged 19-21 months rather than 24 months; some children may receive measles, mumps, and rubella vaccine between 19-21 and 24 months. Secondly, the 10 study districts included many inner city districts where immunisation uptake can be problematic. Thirdly, COVER data are prepared at fixed dates. Local child health staff often make particular efforts to ensure that records are as up to date as possible for this deadline. The data for the present study were collected at a time midway between these deadlines.

Our data confirm that some districts have difficulties in achieving the $90 \%$ target of measles, mumps, and rubella vaccine uptake, and some groups of the client population are less likely to participate in the programme than others. This situation is likely to be more difficult when the target is increased to $95 \%$ in $1995 .^{24}$

The problem of mumps encephalomyelitis following measles, mumps, and rubella immunisation in a small proportion of cases recently identified with certain brands of immunisation containing the urabe strain of mumps and the associated adverse publicity make it critical to avoid a decline in immunisation for measles, mumps, and rubella (and possibly other immunisations) such as followed the adverse publicity associated with possible side effects from pertussis immunisation

\section{Clinical implications}

- The target of $90 \%$ uptake of measles, mumps, and rubella vaccine is not being met in many districts

- Uptake of diphtheria, pertussis, and polio vaccine is the most important predictor for uptake of measles, mumps, and rubella vaccine

- This association suggests that there is a group of children who are unlikely to be vaccinated at all

- Other factors reducing uptake are immunisation provided in health clinics rather than by general practitioners; having many older siblings; change of address; living in inner city districts

- The health service should target families with adverse factors, especially those whose children have missed previous immunisations in the 1970s. Our results suggest that to maintain and improve measles, mumps, and rubella immunisation particular attention should be paid to families who have not had their children vaccinated against diphtheria (pertussis), tetanus, and polio or who had omitted specifically pertussis vaccine, and to larger or one parent families, especially if they live in inner city districts or are registered for immunisation at child health clinics.

The study was based on computerised child health systems. Although the quality of data from the computer system has been questioned by previous studies, particularly those undertaken in inner city areas, ${ }^{25}$ much effort has been made to improve the performance of the systems, especially to increase the capacity of dealing with mobile populations by allowing more efficient exchange of child health information between health professionals or localities. ${ }^{12}$ In fact, the system data have been a major source of local and national statistics on child health services-for example, immunisation uptake rates." Compared with those from "one off" epidemiological surveys, data stored in the systems are routinely collected and therefore are available at no extra cost. The systems provide ongoing data allowing cross sectional and longitudinal analyses and, particularly if standardised and complete data variables can be collected routinely, provide opportunities for ongoing assessments of factors influencing uptake of services.

This study was funded by North East Thames Regional Health Authority. We thank all participant districts for allowing us to use their child health data; Drs E M BoothroydBrooks and A Lloyd-Evans for their invaluable advice; and staff at the computer centre in Royal Free Hospital School of Medicine for their support with the computing.

1 Department of Health and Social Security. Immunisation against infectiou disease. London: HMSO, 1988

2 Walker D, Carter H, Jones I. Measles, mumps and rubella: the need for a change in immunisation policy. BMF 1986;292:1501-2.

3 Measles vaccine once or MMR twice [editorial]. Lancet 1986;ii: 671 .

4 Miller CL. Miller E. Rubella vaccination in the UK: time for a complete strategy. Lancet 1986;ii:732.

5 Campbell AGM. Measles immunisation: why have we failed? Arch Dis Child 1983;58:3-5.

6 White JM, Gillam SJ, Begg NT, Farrington CP. Vaccine coverage: recen trends and future prospects. $B M 7$ 1992;304:682-4.

7 Nicoll A, Elliman D, Begg NT. Immunisation: causes of failure and strategies and tactics for success. BMF 1988;299:808-12.

8 Hertogs D. Tower Hamlets Health Authority measles immunisation initiative 1987-88. Public Health 1989;103:421-6.

9 Hodes DT, Timms SL, Gill ON. A successful measles campaign as a model fo achieving high uptakes of MMR. Public Health 1990;104:27-31.

10 Begg NT, Noah ND. Immunisation targets in Europe and Britain. BM 1985;291:1370-1.

11 White JM, Leon S. "COVER" (Cover of vaccination evaluated rapidly): 22 Communicable Disease Repor 1992;2:R96.

12 Department of Health. Immunisation against infectious disease. London HMSO, 1990.

13 Jarman B. Identification of underprivileged areas. BMJ 1983;286:1704-9.

14 SAS Institute. SAS user's guide: statistics. Version 5. Cary, North Carolina: SAS Institute, 1985

15 Peckham C, Bedford H, Senturia Y, Ades A. The Peckham report-national immunisation study: factors influencing immunisation uptake in childhood. immunisation study: factors influencing immunisation
London: Action Research for the Crippled Child, 1989.

16 Hull D. Why children are not immunised. $f R$ Coll Physicians Lond 1987;21:28-31

$17 \mathrm{Li} \mathrm{J}$, Taylor B. Comparison of immunisation rates in general practice and child health clinics. BMY 1991;303:1035-8.

18 Ritchie LD, Bisset AF, Russell D, Leslie V, Thomson I. Primary and preschool immunisation in Grampian: progress and the 1990 contract. $B M f$ 1992;304:816-9.

19 Jarman B, Bosanquet N, Rice P, Dollimore N, Leese B. Uptake of immunisation in district health authorities in England. BMF 1988;296: $1775-8$.

$20 \mathrm{Li} \mathrm{J}$, Taylor B. Immunisation uptake and family size. Health Trends 1993;25:16-9.

21 Marks JS, Halpin TJ, Irvin JJ, Johnson DA, Keller JR. Risk factors associated with failure to receive vaccination. Pediatrics 1979;64:304-9.

22 Riley DJ, Mughal MZ, Roland J. Immunisation state of young children admitted to hospital and effectiveness of a ward based opportunistic
admong immunisation policy. BMF 1991;302:31-3.

23 Jefferson N, Sleight G, Macfarlane A. Immunisation of children by a nurse without a doctor present. $B M Y$ 1987;294:423-4

24 Secretary of State for Health. Health of the nation. A consultative document for health in England. London: HMSO, 1991. (Cm 1523.)

25 Jefferies S, McShane S, Oerton J, Victor CR, Beardow R. Low immunisation uptake rates in an inner city health district: fact or fiction? F Public Healt Med 1991;13:312-7.

(Accepted 11 May 1993) 